\title{
ANORMALIDADES NEUROMUSCULARES NO DESUSO, SENILIDADE E CAQUEXIA
}

\author{
JOAO ARIS KOUYOUMDJIAN *
}

\begin{abstract}
RESUMO - feita revisão de literatura sobre as principłais alterações do sistema neuromuscular no desuso, senilidade e caquexia no ser bumano e em modèas animais. A diminuiçăo do diâmetro das fibras musculares após perfodo de inatividade/imobilidade (desuso) deve-se à perda de miofibrilas perfféricas não ocorrendo formação de core-targetóides ou diminuiçăo da atividade da miofosforilase, próprias da desnervaçăo; mantêm-se a liberação espontanea de acetilcolina e fatores tróficos na junção mio-neural; em geral são afetadas preferencialmente fibras II, que podem assumir forma angular. Existe um processo continuo intrinseco de envelhecimento de nervos e músculos, com desnervação e reinervaça lenta e progressiva; o número de unidades motoras se reduz após 60 anos, sem ocorrência de atividade elétrica desnervatória; a quantidade de acetilcolina liberada nos neurónios terminais e a capacidade máxima de utilização de oxigênio estão diminuidıs; a redução da capacidade oxidativa mitocondrial pode explicar o aumento de fibras I, mantendo-se o equilíbrio energético. Após poucas semanas de caquexia as fibras musculares podem ter o diametro reduzido em $30 \%$, essa redução ocorre em ordem decrescente nos músculos dos membros inferiores, supertores e tronco; existe atrofia II preferencial com fibras angulares ocasionais, reduçăo de RNA/sintese protelca, mantendo-se DNA normal.
\end{abstract}

PALAVRAS-CHAVE: caquexia, envelhecimento, imobilizaçăo, doenças neuromusculares.

Neuromuscular abnormalitios in disuse, eachexia and ageing.

SUMMARY - Cachexia, ageing and disuse and their effects on the human and animais neuromuscular system are reviewed. Disuse induces reduction of muscle fibers (mainiy II) diameter with peripheral myofibrils lost; there is no core-targetoid or even reduction on myophosphorilase activity, both typical of denervation; the acetylcholine spontaneous release and trophic factors on myoneural junction are maintained; muscle fibers could change to angular shape. Ageing affects nerve and muscle by a continuous and progressive process of denervation and reinnervation; the number of motor units diminishes in sixties without any denervation electric activity; there is also reduction on the amount of ACh release on terminal neurons and mitochondrial oxidative capacity leading to compensatory type I muscle fiber number increase. Cachexia also induces reduction on muscle fibers diameter first on legs and then on arms and trunk; there is type II atrophy with occasional angular fibers, RNA/proteic synthesis reduction and normal DNA.

KEY WORDS: cachexia, ageing, immobilization, neuromuscular diseases.

\section{DESUSO}

A diminuição do diâmetro das fibras musculares que surge após um período de inatividade/imobilidade do músculo esquelético é denominada atrofia de desuso. O tamanho das fibras musculares é determinado por múltiplos fatores, entre os quais, inervação, treinamento, hormônios, crescimento, nutrição e estiramento 14. São bem conhecidas as hipertrofias fisiologicas induzidas por treina-

* Professor Assistente da Disciplina de Neurologia da Faculdade de Medicina de Sto Jose do Rio Preto. Aceite: 3-março-1993.

Dr. João Aris Kouyoumdjian - Av. Bady Bassitt 3896 - 15025-000 săo Jose do Rio Preto SP Brasil. 
mento físico, particularmente naqueles realizados sob um regime de contração isométrica, próxima a máxima, como no caso de halterofilismo; ao contrário. esforços físicos que requerem alternância rápida de movimento - contração isotônica - com habituação à deficiência de oxigênio, como por exemplo em fundistas, induzem a pequena hipertrofia muscular 1,21. A hipertrofia fisiológica não se mantém indefinidamente e o retorno aos diâmetros originais da fibra muscular ocorre proporcionalmente ao tempo em que o treinamento foi efetuado; se, por exemplo, um treinamento de contra-resistência for realizado durante um período de 6 a 12 semanas, induzindo hipertrofia muscular e em seguida descontinuado, o tamanho das fibras musculares diminui em $5 \%$ por semana, até voltar à medida original 1. Do ponto de vista histopatológico, observa-se aumento do sarcoplasma e do número de miofibrilas, mantendo-se constante seu tamanho. O músculo, portanto, tem a propriedade única de aumentar de tamanho com a atividade - hipertrofia fisiológica - e inversamente, diminuir com a inatividade - atrofia de desuso. No ser humano a atrofia de desuso é comumente observada em imobilizações por problemas ortopédicos, em indivíduos cronicamente acamados, em artropatias dolorosas, artroses e em síndromes motoras centrais (síndromes piramidais e extrapiramidais). Os achados histopatológicos na atrofia de desuso incluem diminuição no diâmetro e comprimento das fibras musculares, alterações no tipo de fibra muscular e alterações ocasionais não específicas de cito-arquitetura. A anormalidade mais marcante é a diminuição no diâmetro das fibras que geralmente assumem morfologia angular, afetando igualmente os tipos I (vermelha, oxidativa e tônica) e II (branca, glicolítica e fásica). A proporção dos subtipos I e II depende da atividade e função específica do músculo envolvido. O tamanho médio das fibras do músculo Quadriceps femoris, por exemplo, diminuiu cerca de $50 \%$ em relação a grupos controles normais após imobilização de oito semanas 9 . No desuso de maneira geral, encontra-se atrofia preferencial II 12, porém pode se encontrar atrofia IIB na artrite reumatóide 5 , atrofia I após tenotomia 13, atrofia I/II com aumento no número de fibras II em compressões medulares ${ }^{6}$ e atrofia II com hipertrofia I ocasional na espasticidade e doença de Parkinson 10. Existe perda de miofibrilas periféricas da fibra, o retículo sarcoplasmático fica maior que o usual e o número de mitocôndrias diminui paralelamente ao de miofibrilas 23 . Não ocorre formação de fibras com anormalidade de citoarquitetura tipo core-targetoide. As anormalidades ultra-estruturais na atrofia de desuso são semelhantes ao do estágio inicial da atrofia por desnervação 18. A ausência de fibras core-targetóides, que estão presentes na desnervação, e a presença normal de atividade da miofosforilase, que está ausente na desnervação, são dados contrários à teoria da base neurogênica com envolvi mento secundário do músculo na atrofia de desuso 25 . Não existe relação linear entre o grau de atrofia e a duração de imobilização; determinados músculos atrofiam mais precocemente que outros pela inatividade, sendo o músculo da língua o mais resistente. Não existe, ainda, relação entre o grau de atrofia e o diâmetro do membro imobilizado. O tempo de desenvolvimento da atrofia depende do grau de estiramento do músculo; a imobilização do membro com músculo estirado retarda o desenvolvimento da atrofia, podendo até hipertrofiar as fibras, com aumento do número de sarcômeros até a tensão máxima ser novamente desenvolvida 32; a imobilização do membro encurtado acelera o aparecimento de atrofia e diminui o número de sarcômeros. A atrofia de desuso e a atrofia de desnervação originam quadros semelhantes, em graus diferentes, no sentido que diminuem o potencial de repouso da membrana, diminuem a síntese proteica, diminuem a acetil-colinesterase muscular, induzem o aparecimento de receptores de acetilcolina extrajuncionais e brotamento axonal em fibras nervosas intramusculares. Contudo, apenas na atrofia de desuso, mantém-se a liberação espontânea de acetilcolina e de fatores tróficos não identificados na junção mioneural.

Os estudos em animais podem ser feitos através de vários métodos 22 , entre os quais fixação esquelética/imobilização para restrição da atividade muscular, secção do tendão muscular, secção medular (cordotomia), secção medular associada à secção de raízes dorsais (isolamento muscular), anestesia do nervo periférico, compressão ou bloqueio do nervo periférico com tetrodotoxina (TTX) que atua bloqueando os canais de sódio do axolema, abolindo assim a condução axonal e preservando o transporte axonal rápido e a liberação espontânea de acetilcolina.

As alterações histológicas dos músculos Gastrocnemius, Soleus e Flexor digitorum longus, descritas pós-imobilização dos membros posteriores de gatos 8 , 
incluem: perda das miofibrilas periféricas, aumento da proeminência nuclear e diminuição do diâmetro das fibras (pós 2 semanas); alguns núcleos centrais, afastamento de miofibrilas, degeneração vacuolar por perda de elementos contráteis centrais e acentuação da diminuição do diâmetro das fibras com irregularidade de forma (pós 4 semanas); algumas fibras ou fascículos com edema e degeneração hialina evoluindo para degeneração granular com desaparecimento de todos os tubos sarcolemais (pós 6 a 22 semanas). A membrana basal na maioria das fibras fica preservada e sua integridade é pré-requisito indispensável para a regeneração efetiva das fibras musculares. Em algumas fibras, as células satélites se tornam proeminentes e representam células potencialmente formadoras de novas fibras musculares. Macrófagos adjacentes aumentam em número e existe proliferação de tecido conjuntivo e adiposo. Uma semana após a retirada da imobilização, as fibras revelam intensa atividade regenerativa com grandes núcleos vesiculares arredondados subsarcolemais, contrastando com núcleos picnóticos das fibras atrofiadas. A regeneração linear cresce cerca de $1,5 \mathrm{~mm}$ ao dia; em três meses a maioria das fibras atinge tamanho normal.

Gatos submetidos a isolamento medular mostraram pequena atrofia tipo I e retenção das propriedades histoquímicas do músculo até trinta dias 18 . A atividade da mio-fosforilase que se reduz rapidamente na atrofia por desnervação é bem preservada nesse periodo.

Cobais submetidas a cordotomia, fixação esquelética e desnervação por secção do nervo ciático 17 mostraram que o músculo Gastrocnemius (músculo misto . fibras I e II) apresenta atrofia de fibras I e II pós cordotomia e fixação esquelética e atrofia tipo II associada à perda precoce da atividade fosforilásica pós desnervação. Já no músculo Soleus (músculo apenas com fibras I) aparecem fibras II precocemente pós cordotomia (principalmente) e pós desnervação; conclui-se que influências superiores são necessárias para que esse músculo mantenha apenas fibras I; a conversão para músculo misto pós desnervação é mais lenta.

Gatos submetidos a tenotomia dos músculos Gastrocnemius e Soleus 13 apresentaram atrofia I e hipertrofia II. A atrofia I pode ocorrer devido ao relaxamento do fuso muscular com redução de aferências à medula e consequente diminuição da atividade reflexa; a hipertrofia II poderia ocorrer por aumento da atividade voluntária para superar a deficiência motora. Tais anormalidades são dependentes da ativação neuronal associada a tenotomia.

As propriedades histoquímicas das fibras musculares são reguladas neuralmente; as fibras II reinervadas por nervo originalmente para fibra I são convertidas para esse último. A unidade motora, portanto, contém fibras musculares de um mesmo tipo histoquímico, pois o tipo de ativação neuronal é semelhante. Motoneurônios descarregam em baixa frequência $(10-20 \mathrm{~Hz}$ ) para fibras I e em alta frequência $(30-60 \mathrm{~Hz})$ para fibras II. Gatos submetidos a isolamento medular revelaram atrofia seletiva de fibras II que normalizaram após estimulação fásica ou tônica 26. Apesar da regulação neuronal sobre os tipos histoquímicos, a atividade neuronal uniforme de todas as fibras em um músculo misto não conduz à uniformidade de fibras; portanto, a diferenciação do tipo de fibra muscular não é determinado exclusivamente pelo padrão de impulso neuronal.

Membros posteriores de ratos fixados em flexão plantar ou em dorsiflexão, de tal sorte que os músculos Gastrocnemius/Soleus e Tibialis anterior ficassem encurtados ou estirados, revelaram grau e tempo de desenvolvimento de atrofia diferentes 4. Atrofia mais intensa e rápida ocorreu em músculos imobilizados em posição encurtada. Quando os músculos são imobilizados em posição estirada, o início da atrofia é retardado, podendo ocorrer até hipertrofia de fibras musculares. A tensão do músculo, mesmo em estado de desuso, parece proteger contra atrofia. O número de sarcômeros no músculo encurtado diminui e no estirado aumenta até que a tensão máxima possa ser novamente desenvolvida 32 .

\section{SENILIDADE}

O declínio do performance muscular com o avançar da idade está muito bem estabelecido. Apesar de muitos fatores extrínsecos ao músculo, tais como desnutrição, desuso, insuficiência circulatória e neoplasias ocultas contribuirem para a sintomatologia neuromuscular da senilidade, o processo contínuo de enve- 
lhecimento realmente existe como um fator intrínseco a nervo e músculo. A força de preensão palmar diminui pela metade entre 25 e 79 anos de idade; são comuns os achados de atrofia nos músculos intrínsecos da mão e cintura pélvica, com déficit motor associado. O volume muscular global, a velocidade de contração e a força muscular começam a diminuir a partir dos 50 anos. A perda de força, diminuição da agilidade e atrofia muscular, deixando membros finos e flácidos, associados à sintomatologia senil relacionada ao sistema nervoso central como tremor, hipocinesia, incoordenação e aumento do tono muscular de repouso (paratonia), fazem com que o complexo sintomático neuromuscular seja frequente na senilidade $1,7,14,16,21$.

Relativamente à eletrofisiologia, podemos encontrar diminuição da amplitude da onda $M$ e da tensão máxima de contração muscular. O número de unidades motoras se reduz após 60 anos, não ocorrendo nesse processo atividade elétrica de desnervação ao repouso (fibrilaçōes e ondas positivas). As unidades motoras remanescentes aumentam sua área incorporando novas fibras musculares de unidades motoras perdidas por "sprouting" ou brotamento axonal; dessa forma os potenciais de unidades motoras aumentam em amplitude e duração, achados compatíveis com reinervação. Essa reinervação é contudo limitada, pois os potenciais não ficam tão grandes como na reinervação de indivíduos jovens. Alguns músculos, como por exemplo Extensor digitorum brevis, podem perder mais de $50 \%$ de suas unidades motoras após 70 anos de idade. Ratos podem perder 18 a 38\% de motoneurônios do corno anterior medular na senilidade 3; camundongos sofrem a mesma perda na faixa de 15 a $20 \% 34$. No ser humano, aproximadamente $25 \%$ dos motoneurônios da medula lombo-sacra são perdidos entre a juventude e a velhice, ocorrendo principalmente a partir de 60 anos de idade 28. A quantidade de acetilcolina liberađa nos axônios terminais diminui e às vezes não é suficiente para iniciar o potencial de ação na fibra muscular, estando portanto funcionalmente desnervada.

A capacidade máxima de utilização de oxigênio diminui na senilidade, sendo que o treinamento físico melhora apenas parciaimente esse quadro, mostrando que fatores intrínsecos inexoravelmonte ocorrem no sistema. Apesar da capacidade metabolica muscular estar estreitamente relacionada com o performance físico muscular, o declinio deste na senilidade não pode ser explicado em termos de deterioração do metabolismo energético muscular 24 . A diminuição do metabolismo basal no idoso deve se em grande parte à diminuição da massa ativa responsável pelo consumo de oxigênio, quais sejam, músculos e órgãos vitais; como esses últimos não decrescem em proporções consideráveis, a massa muscular deve ser totalmente responsável pelo decréscimo do metabolismo basal na senilidade 30 . O número total de mitocôndrias é constante na fibra muscular porém o volume total, principalmente subsarcolemal diminui com o avançar da idade, independentemente da atividade física; portanto, para manter o mesmo ritmo de atividade é necessário aumentar a capacidade oxidativa por unidade de volume mitocondrial. Isso poderia explicar em parte, como será visto adiante, o notável aumento no número de fibras tipo I (oxidativas) na senilidade, mantendo-se assim o equilíbrio energético. A diminuição da síntese de RNA e do turnover proteico sugere que a capacidade das fibras musculares em renovar componentes e reparar graus leves de lesões celulares diminui na senilidade.

As anormalidades histológicas e histoquímicas das fibras musculares na senilidade são importantes e documentadas em vários relatos. As alteraçóes regressivas do músculo esquelético se iniciam a partir da vida adulta média; existe reducão global no número de fibras musculares, fibras isoladas podem apresentar atrofia e algumas outras podem até se hipertrofiar secundariamente 2 . Existe variação no diâmetro das fibras musculares e isso deve-se principalmente a atrofia de fibras I e II de ordem neurogênica ou a atrofia de fibras II de ordem funcional, desuso ou caquexia. Existe frequente desnervação e reinervação no músculo esquelético de pessoas idosas pela perda progressiva, como já visto, de unidades motoras com aumento na área de inervação das remanescentes por brotamento axonal; isso conduz a agrupamentos de fibras com o mesmo tipo histoquímico I ou II. Alterações estruturais podem ser observadas tais como core-targetóides e distribuição irregular da atividade enzimática oxidativa nas fibras I. Outra anormalidade marcante é o aumento progressivo na proporção de fibras I com o avançar da idade. Biópsias do músculo Quadriceps femoris do homem mostraram que as fibras I respondiam a $40 \%$ do total na terceira década de vida 
$e$ por $65 \%$ na faixa de 60-65 anos 19 . Esse desvio preferencial para fibras I na senilidade pode ocorrer por: 1. desnervação preferencial com perda de fibras II; 2. reinervação de fibras II previamente desnervadas, por motoneurônios funcionalmente para fibras I; 3. transformação de fibras II em I por alterações das propriedades funcionais dos motoneurônios ou da atividade física do paciente 14 A diminuição da contração isométrica do músculo se correlaciona à diminuição da proporção e atrofia de fibras II na senilidade, contribuindo para o declínio da força muscular 20 . Grânulos de lipofuscina estão invariavelmente presentes no tecido muscular de idosos e geralmente se acumulam em regióes subsarcolemais próximo ao núcleo e principalmente em fibras I; são considerados como corpos residuais dos lisossomos e devem ser originados da peroxidação de ácidos graxos insaturados. Pode haver, ainda, aumento focal de núcleos sub-sarcolemais e agregados esparsos de núcleos picnóticos em áreas de atrofia agrupada considerável. Niuito ocasionalmente podem ocorrer fibras musculares com perda de estriações, degeneração hialina, necrose/fagocitose e proliferação conjuntivo gordurosa. Os fenómenos regenerativos são pouco comuns na senilidade e parece que existe perda de células satélites; essa redução pode contribuir para a diminuição da capacidade regenerativa que em última análise, pode conduzir à perda de fibras musculares. As anormalidades detectadas são, portanto, muito mais sugestivas de atrofia neurogênica, com poucas fibras sugerindo padrão miopático 15. As alterações neurogênicas são maiores nos músculos distais dos membros inferiores, sendo na ordem decrescente, Extensor digitorum brevis, Flexor digitorum brevis, Tibials anterior e Gastrocnemius; o músculo Extensor digitorum brevis pode apresentar características neurogênicas em adultos jovens, sendo portanto uma exceção entre as anormalidades próprias da senilidade 14 .

\section{CAQUEXIA}

A caquexia induzida por câncer sistêmico, tuberculose, sprue e principalmente subnutrição, que representa sua causa mais comum, invariavelmente conduz à perda de tecido adiposo subcutâneo e à diminuição global do volume muscular. Ratos submetidos a regimes carenciais proteicos apresentam diminuição do volume/peso muscular, RNA e síntese proteica, mantendo-se DNA normal 14. A análise de diferentes músculos nesses mesmos animais, incluindo-se os de membros anteriores, posteriores e tronco, revelou que as alterações em certos índices químicos e bioquímicos variam de acordo com a localização anatôinica deles 27. Assim, a perda de peso, a diminuição do ccniteúáo de agua, da proteína ceiular (mioniiorilar e sarcopiasmática) e do RNA foram mais acentuados na mus. culatura do tronco, ocorrendo em menor grau nos membros anteriores, principalmente músculos distais; o tipo de musculatura, fásica ou tônica, não influenciou nos diferentes graus de acometimento sob regime de desnutrição. O crescimento da musculatura de panturrilha de ratos é $20 \%$ menor, comparando-se proles de 16 com proles de 8 animais, mostrando a grande sensibilidade do músculo à subnutrição neonatal ${ }^{33}$. Não existe diferença no grau de retardo do crescimento muscular em ratos jovens subnutridos em relação ao sexo, porém fêmeas apresentam um crescimento compensatório (crescimento com velocidade acima dos limites estatísticos normais para a idade) maior após a retirada do fator de retardo. Do ponto de vista histológico e histoquímico, ratos submetidos a até 22 dias de jejum apresentaram atrofia de fibras I e II (principalmente II) com fibras angulares ocasionais e maior proporção de fibras necróticas em relação aos controles; tal quadro foi semelhante ao encontrado em ratos tratados com glicocorticóides 31 . A microscopia eletrônica, observou-se desorganização ou dissolução das miofibrilas sem estimulação lisossômica.

No homem, achados de necrópsia em vários músculos revelaram que após casos leves de caquexia, as fibras apresentavam discreta atrofia predominantemente II com fibras angulares ocasionais; após casos graves, a atrofia era mais acentuada, apresentando-se em grupos extensos, maior em membros inferiores 29 . As fibras musculares podem diminuir $30 \%$ em poucas semanas de caquexia. A desnutrição proteica em crianças pode reduzir as fibras musculares a tamanhos fetais e diminuir o número de células satélites. Os núcleos sarcolemais aumentam em número e tamanho numa primeira etapa, podendo ocorrer fileiras de núcleos pequenos e picnóticos posteriormente; o sarcoplasma apresenta-se reduzido em tamanho com condensação de miofibrilas; as mitocôndrias diminuem em número e tamanho; as estriações estão mantidas. A proliferação de macrófagos é pequena 
devido à degeneração apenas ocasional e não hialina das fibras musculares. A hipertrofia de fibras musculares isoladas é rara e a proliferação de novas fibras é reduzida. O glicogênio muscular não é modificado ${ }^{1}$. Assim, como foi demonstrado em animais, o efeito da caquexia no músculo esquelético do homem pode ser mais intenso em alguns segmentos do que em outros; os músculos mais acometidos são de membros inferiores, seguidos dos superiores e tronco. Na Tabela 1 são sumariados os principais achados histológicos e histoquímicos do músculo no desuso, senilidade e caquexia no ser humano e em modelos animais.

Tabela 1. Desuso, senilidade e caquexia: sumário das anormalidades histopatol6gicas/histoqui. micas no ser humano e em modelos animais experimentais.

Procedimento ou
condição clinica $\quad$ Anormalidades histopatológicas/histoquimicas Fonte

Modelos animais

$\begin{array}{cl}\text { Tenotomia } & \begin{array}{l}\text { Atrofia I e hipertrofia II. } \\ \text { Target e core-targetóides em fibras I; corpos } \\ \text { nemalínicos; necrose; massas sarcoplasmáti- } \\ \text { cas; vacúolos centrais; variabilidade coloração } \\ \text { enzimática oxidativa. }\end{array} \\ \text { Isolamento medular } & \text { Atrofia II (IIB). Aumento de fibras II. } \\ \text { Cordotomia } & \text { Atrofia I e II. } \\ & \text { Necrose; aumento tecido conjuntivo endomisial } \\ & \text { e adiposo; fibras arredondadas hipertrofiadas; } \\ \text { fibras em anel; aumento no número de núcleos } \\ \text { centrais; vacuolizacão; core-targetóides. } \\ \text { Fixação articular } & \text { Atrofia I e II. Aumento de fibras II. } \\ \text { Caquexia } & \text { Atrofia I e II (maior II). } \\ & \text { Fibras angulares ocasionais; raras fibras ne- } \\ \text { cróticas. }\end{array}$

Desuso geral

Imobilização e fixação esquelétioa

Artrite reumatóide

Artrite reumatóide dolorosa

Compressão medular

Espasticidade/Parkinson

Exercício isométrico

Exercício isotonico

Senilidade
Atrofia II.

Atrofia I, II ou I/II.

Atrofia IIB.

Atrofia I (associado: atrofia IIA e hipertrofia IIB).

Atrofia I e II. Aumento de fibras II.

6

Atrofia II. Hipertrofia I ocasional.

10

Grande hipertrofia II.

21

Leve hipertrofia II.

21

Atrofia I/II ou II.

Predomínio de fibras I. Agrupamentos I ou II. Leve aumento de núcleos; agrupamento de núcleos picnóticos; core-targetóides; acúmulos de lipofuscina; discreta proliferaçăo conjuntivo-fibrosa; distribuição irrregular da atividade enzimática oxidativa.

Atrofia predominantemente II. Fibras angulares isoladas. 


\section{REFERENCIAS}

1. Adams RD. Diseases of muscle: a study in pathology. Ed 3. Hagerstown: Harper \& Row, 1975, pp 100-102, 139-140, 457-460.

2. Astrom KE, Adams RD. The pathological reactions of the skeletal muscle fiber. In: Vinken PJ, Bruyn GW. Hiandbook of Clinical Neurology. Amsterdam: Elsevier/NorthHolland, 1979, Vol 40, p 197-200.

3. Bari and Andrew. In: McComas AJ. Neuromuscular function and disorders. London: Butterworths, 1977, p 106.

4. Booth FW. Time course of muscular atrophy during immobilization of hindlimbs in rats. J Appl Physiol 1977, 43:656-661.

5. Brooke MH, Kaplan H. Muscle pathology in rheumatoid arthritis, polymyalgia rheumatice and polymyositis. Arch Pathol 1972, 94:101-118.

6. Bundschun HD, Suchenwirth $R$, Dlavis W. Histochemical changes in disuse atrophy of human skeletal muscle. In: Kakulas BA. Basic research in myology, part I. Proceedings of the 2nd International Congress on Muscle Diseases. Amsterdam: Excerpta Medica. Internat Congr Series 294, 1973, p 108.

7. Campbell MJ, McComas AJ, Petito F. Physiological changes in ageing muscles. J Neurol Neurosurg Psychiatry 1973, 36:174-182.

8. Cooper RR. Alterations during immobilization and regenerating of skeletal muscle in cats. J Bone Joint Surg 1972, 54-A:919-953.

9. Dastur DK, Gagrat BM, Manghani DK. Human muscle in disuse atrophy. Neuropathol Appl Neurobiol 1979, 5:85-91.

10. Edstrom $L$. Selective changes in the sizes of red and white muscle fibres in upper motor lesions and parkinsonism. J Neurol Sci 1970, 11:537-550.

11. Edstrom L. Selective atrophy of red muscle fibers in the Quadriceps in long-standing knee joint dysfunction: injuries to the anterior cruciate ligament. $J$ Neurol Sci 1970, $11: 551-558$.

12. Engel WK. Histochemistry of neuromuscular disease: significance of muscle flber types. Proceedings of the International Congress of Neurology 2. Amsterdam: Excerpta Medica, 1965, p 67 .

13. Engel WK, Brooke MH, Nelson PG. Histochemical studies of denervated or tenotomized cat muscle: illustrating difficulties in relating experimental animal conditions to human neuromuscular diseases. Ann N Y Acad Sci 1966, 138:160-185.

14. Jennekens FGI. Disuse, cachexia and ageing. In: Mastaglia F, Walton J. Skeletal muscle pathology. London: Churchill Livingstone, 1982, p 605-620.

15. Jennekens FGI, Tomlinson BE, Walton JN. Histochemical aspects of five limb muscles in old age: an autopsy study. J Neurol Sci 1971, 14:259-276.

16. Jenkyn LR, Reeves AG, Warren T, Whiting RK, Clayton RJ, Moore WW, Rizzo A, Tuzun IM, Bonnett JC, Culpepper BW. Neurologic signs in senescence. Arch Neurol 1985, 42:1154-1157.

17. Karpati G, Engel WK. Correlative histochemical study of skeletal muscle after suprasegmental denervation, peripheral nerve section and skeletal fixation. Neurology 1968, 18:681-692.

18. Klinkerfuss GH, Haugh MJ. Disuse atrophy of muscle. Histochemistry and electron microscopy. Arch Neurol 1970, 22:309-320.

19. Larsson L, Sjodin B, Karlsson J. Histochemical and biochemical changes in human skeletal muscle with age in sedentary males, age 22-65 years. Acta Physiol Scand 1978 , 103:31-39.

20. Larsson L, Grimby G, Karlsson J. Muscle strenght and speed of movement in relation to age and muscle morphology. J Appl Physiol (Respiratory, Environment and Exercise Physiology) 1979, 46:451-456.

21. McComas AJ. Neuromuscular function and disorders. London: Butterworths, 1977, pp 80$88,101-108$.

22. Mendell JR. Experimental myopathies. In: Vinken PJ, Bruyn GW. Handbook of Clinical Neurology. Amsterdam: Elsevier North-Holland 1979, Vol 40, Part I, p 133-148.

23. Mendell JR, Engel WK. The fine structure of type II muscle fiber atrophy. Neurology 1971, 21:358-365.

24. Orlander J, Kiessling K-H, Larsson L, Aniansson A. Skeletal muscle metabolism and uitrastructure in relation to age in sedentary men. Acta Physiol Scand 1978, 104:249-261.

25. Patel AN, Razzak ZA, Dastur DK. Disuse atrophy of human skeletal muscles. Arch Neurol 1969, 20:413-421.

26. Riley DA, Allin EF. The effects of inactivity, programmed stimulation and dennervation on the histochemistry of skeletal fiber types, Exp Neurol 1973, 40:391-413. 
27. Spence CA, Hansen-Smith FM. Comparison of the chemical and biochemical composition of thirteen muscles of the rat after dietary protein restriction. B Nutrition 1977, 39: 647-658.

28. Tomlinson BE, Irving D. The number of limb motor neurons in the human lumbosacral cord thoughtout life. J Neurol Sci, 1977, 34:213-219.

29. Tomlinson BE, Walton JN, Rebeiz JJ. The effects of ageing and cachexia upon skeletal muscle: a histopathological study. J Neurol Sci 1969, 9:321-346.

30. Tzankoff SP, Norris AH. Effects of muscle mass decrease on age-related BMR changes. Appl Physiol (Respiratory, Enviroment and Exercise Physiology) 1977, 43:1001-1006.

31. Walsh G, DeVivo D, Olson W. Histochemical and ultrastructural changes in rat muscles: occurrence following adrenal corticotrophic hormone, glucocorticoids and starvation. Arch Neurol 1971, 24-83-93.

32. Williams PE, Goldspink $G$. Changes in sarcomere lenght and physiological properties in immobilized muscle. J Anatomy 1978, 127:459-468.

33. Williams JPG, Hughes PCR. Muscle growth during neonatal undernutrition and subsequent rehabilitation in the rat. Acta Anatomica 1978, 101:249-254.

34. Wright EA, Spink JM. A study of the loss of nerve cells in the central nervous system in relation to age. Gerontologia 1959, 3:277-287. 